\title{
Gluconic acid/gluconolactone: physiological influences on domoic acid production by bacteria associated with Pseudo-nitzschia multiseries
}

\author{
Makoto Osada*, James E. Stewart** \\ Marine Environmental Sciences Division, Science Branch, Department of Fisheries and Oceans, \\ Bedford Institute of Oceanography, PO Box 1006, Dartmouth, Nova Scotia, Canada B2Y 4A2
}

\begin{abstract}
A single strain of Pseudo-nitzschia multiseries was grown axenically and in paralle] cultures to which selected bacterial species isolated previously from $P$. multiseries cultures were added (non-axenic culture), an Alteromonas sp. (a producer of gluconic acid/gluconolactone when grown with glucose) and a Moraxella sp. (a non-producer of gluconic acid/gluconolactone). When gluconic acid/gluconolactone was added to the axenic culture the production of domoic acid was increased to double that produced by the non-axenic culture. The effect of the gluconic acid/gluconolactone on domoic acid production was concentration dependent and could be offset completely by the addition of glutamic acid or proline to cultures containing gluconic acid/gluconolactone. Domoic acid, depending upon culture conditions, was partitioned in varying percentages between the diatom cells and the culture filtrates. It is suggested that the enhancement of the algal production of domoic acid in the presence of specific bacteria could be influenced by production of gluconic acid/gluconolactone by bacteria; this effect may be a direct result of the antagonistic effect of the powerful sequestering properties of gluconic acid which, through tying up nutrients, induces the diatom to produce a counter chelating agent, domoic acid.
\end{abstract}

KEY WORDS: Gluconic acid/gluconolactone Domolc acid - Bacteria Diatom Pseudo-nitzschia multiseries

\section{INTRODUCTION}

The neurotoxic properties of domoic acid were demonstrated in 1987 by a major episode of acute human poisoning (Bird et al. 1988, Subba Rao et al. 1988, Bates et al. 1989, Wright et al. 1989, Perl et al. 1990, Todd 1990, 1993). These reports showed the episode was caused by consumption of cultured blue mussels Mytilus edulis from the tidal Cardigan River and estuary (Prince Edward Island, Canada) which possessed high concentrations of domoic acid, up to $900 \mu \mathrm{g} \mathrm{g}^{-1}$ (Quilliam et al. 1989, Wright et al. 1989). The domoic acid was produced by a diatom, then

\footnotetext{
- Permanent address: Laboratory of Aquacultural Biology, Faculty of Agriculture, Tohoku University, Sendai 981, Japan " Addressee for correspondence.

E-mail: james.stewart@maritimes.dfo.ca
}

called Nitzschia pungens, a bloom of which was serving at that time as the major food source for the mussels (Subba Rao et al. 1988, Bates et al. 1989). At least 3 people died as a result of the domoic acid poisoning and over 150 others were believed to have been poisoned (Perl et al. 1990). As the severe domoic acid intoxications caused memory loss, among other effects, it was named Amnesic Shellfish Poisoning (ASP) (Perl et al. 1990).

Since 1987, investigators have been more alert to the possible presence of domoic acid in the marine environment and, as a consequence, it has been detected at low levels (usually less than $20 \mathrm{\mu g} \mathrm{g}^{-1}$ of the soft tissue) periodically and widely, e.g. in sea scallops Placopecten magellanicus from Eastport, Maine, USA, bay scallops Argopecten irradians from Nantucket Shoals and Georges Bank, USA, blue mussels Mytilus edulis and clams Mya arenaria from the Bay of Fundy, 
Canada; as well domoic acid was shown to be produced by several species of the diatom including one from the Gulf of Mexico (reviewed by Villac et al. 1993 who referred to the diatom by the identifier, Pseudonitzschia pungens f. multiseries). Domoic acid outbreaks have also occurred on the west coast of North America, causing the death of pelicans and cormorants in Monterey Bay, California, which had fed on anchovies contaminated with domoic acid; levels of domoic acid which exceeded legal standards have been recorded in razor clams and Dungeness crabs along the coasts of California, Oregon and Washington (reviewed by Villac et al. 1993).

As a result of these episodes comprehensive monitoring programs have been initiated utilizing costly high performance liquid chiomatography (IIPLC) to test shellfish for domoic acid prior to their being approved for sale. In addition, programs to develop more rapid and direct methods for detecting domoic acid were begun. One involved ion mobility spectrometry (IMS) applied directly to raw mussel fluids (McLachlan et al. 1993) which detected a marker compound. Although the marker compound was present without exception only in those mussels (more than 200 mussels) shown separately, by HPLC, to contain domoic acid, the marker compound was not domoic acid; domoic acid, as determined by IMS, exhibits a lesser peak at a different place in the spectrum (D. G. McLachlan \& A. H. Lawrence pers. comm.). Application of mass spectrometry to the marker compound showed it to be gluconolactone (McLachlan et al. 1993) which was present at concentrations of around $1 \times$ $10^{-7} \mu \mathrm{g} \mathrm{ml} \mathrm{m}^{-1}$ of mussel fluid (D. G. McLachlan \& A. H. Lawrence pers. comm.). Collaborative work with McLachlan and Lawrence by one of us (J.E.S.) showed that extracts from bacteria, isolated from close associations with the domoic acid producing diatom, contained a compound similar to the marker compound, gluconolactone. This was of particular interest as Douglas \& Bates (1992) and Bates et al. (1995) had shown that although axenic cultures of the diatom produce some domoic acid, those cultures which were associated with bacteria produced larger amounts

Preliminary studies in our laboratory showed that gluconolactone or more properly an equilibrium mixture of delta gamma lactones and gluconic acid, a powerful sequestering agent (Merck Index; Windholz 1983), glutamic acid and proline alone and in various combinations over a series of concentrations had direct effects on the cell appearance and growth of the diatom. Thus, we undertook to investigate the effect the gluconic acid/gluconolactone mixture had on domoic acid production by the diatom now raised to the status of a full species and renamed Pseudonitzschia multiseries (Hasle 1995).

\section{MATERIALS AND METHODS}

The diatom used throughout this study was isolated originally from New London Bay, Prince Edward Island, on October 18, 1991, by Kevin Pauley, who designated it KP-59 and, after examining it by scanning electron microscopy and acquiring proof of domoic acid production, attached the name Pseudonitzschia pungens f. multiseries, now altered to Pseudo-nitzschia multiseries (Hasle 1995). Axenic P. multiseries subcultures were prepared by treating non-axenic liquid cultures with the antibiotic ampicillin $\left(1 \mathrm{mg} \mathrm{ml}^{-1}\right.$ of culture medium) overnight, followed by subculture in fresh antibiotic-free medium. Subcultures were examined microscopically and bacteriologically using DrFCo Marine Ag̣â and Broth (\#2216). The subcultures in which no bacteria were observed or could be cultured were used for axenic studies; identical examinations were carried out after the completion of studies to ensure that the cultures were still axenic. Diatom numbers were determined by direct microscopic counts on samples removed from the growth flasks, mixed with fixative $(2 \%$ final concentration of $1: 1$ formalin:glacial acetic acid) and settled in glassbottomed counting chambers.

All diatom growth studies were carried out in duplicate or triplicate and performed at $20^{\circ} \mathrm{C}$ in a continuous cool-white fluorescent light regime measuring $170 \pm 30 \mu \mathrm{mol} \mathrm{m} \mathrm{m}^{-2} \mathrm{~s}^{-1}$ (QSL light meter, Biospherical Instruments Inc.). The growth medium was a modification of that proposed by Harrison et al. (1980); the steam-sterilized trace metals and nutrients (minus the silicate and boric acid and with $\mathrm{NaH}_{2} \mathrm{PO}_{4}$ substituted for glycerophosphate) were added aseptically to steamsterilized natural sea water (taken from bulk supplies collected from Bedford Basin in the fall of 1990, passed through a $53 \mu \mathrm{m}$ pore size filter and stored unsterilized in closed containers at room temperature) followed by the aseptic addition of the vitamin mixture and $1 . \mathrm{mll}^{-1}$ $(0.035 \mathrm{~g})$ of a $\mathrm{Na}_{2} \mathrm{SiO}_{3} \cdot 9 \mathrm{H}_{2} \mathrm{O}$ sterile solution to give a final silicate concentration of $0.123 \mathrm{mM}$.

The 2 bacterial species used had been isolated earlier from a Pseudo-nitzschia multiseries culture. In a separate study (Stewart et al. 1997, in this issue), one was identified as an Alteromonas sp. which produced gluconic acid/gluconolactone from glucose and the other as a Moraxella sp. which did not produce gluconic acid/gluconolactone. Marine Agar was used for maintenance of the bacteria, checks on their presence, and for counting colony-forming units (cfu) in serial dilutions of the algal medium.

To determine the effect of bacteria on the production of domoic acid by Pseudo-nitzschia multiseries, the Alteromonas and Moraxella sp. were washed from agar slants with sterile $3 \% \mathrm{NaCl}$ and added to axenic 
cultures of $P$. multiseries to give the cultures referred to in this report as non-axenic. These were also cultured at $20^{\circ} \mathrm{C}$ in continuous light and were transferred at 2 wk intervals to ensure cultural stability prior to their use in the experiments.

Glutamic acid, proline, glucose (Sigma Chemical Co.) and gluconic acid/gluconolactone (BDH Chemicals Ltd) were dissolved in the algal culture medium and adjusted with $\mathrm{NaOH}$ to $\mathrm{pH}$ 8.0. Appropriate volumes of these solutions sterilized by filtration $(0.22 \mu \mathrm{m}$ pore size filters) were added to the standard growth volume of $20 \mathrm{ml}$ in the culture flasks $(50 \mathrm{ml}$ capacity polystyrene sterile tissue culture flasks, Nunc Inc.) at the beginning of the experiments or at Day 6 of the growth period.

From each culture flask $2 \mathrm{ml}$ was removed every 4 or $6 \mathrm{~d}$ and the cells were sedimented by centrifugation $\left(500 \times g\right.$ for $10 \mathrm{~min}$ at $\left.4^{\circ} \mathrm{C}\right)$ to provide the culture filtrates containing the extracellular domoic acid. These filtrates were stored at $-80^{\circ} \mathrm{C}$ for later determination of the domoic acid. The sedimented Pseudo-nitzschia multiseries cells were resuspended in $3 \% \mathrm{NaCl}$. washed twice by centrifugation $(500 \times g)$ and finally resuspended in $2 \mathrm{ml}$ phosphate-buffered saline (PBS; $10 \mathrm{mM}$ phosphate buffer at pH 7.2 containing $0.85 \%$ $\mathrm{NaCl}$. The suspended cells were then ruptured by treatment for $1 \mathrm{~min}$ with a Sonic Dismembrator 300 (Artek System Corporation) equipped with a titanium microtip and operated at 35\% maximum power (ca $100 \mathrm{~W})$. The resulting homogenate was centrifuged $(10000 \times g$ for $10 \mathrm{~min})$ to remove debris; the resulting supernatant fluid, which now contained the intracellular domoic acid, was stored at $-80^{\circ} \mathrm{C}$ to await analysis.

Domoic acid analyses were performed using an enzyme-linked immunosorbent assay (ELISA) shown to be specific for domoic acid (range 0.1 to $1000 \mathrm{ng}$ domoic acid $\mathrm{ml}^{-1}$ ) and to exhibit no cross reactions with kainic acid, glutamic acid or proline (Osada et al 1995). For these analyses $182 \mu \mathrm{l}$ of each cellular extract or 10-fold PBS dilutions of the extracellular material (culture filtrates) was dispensed in 96-well microplates previously coated with domoic acid conjugated with ovalbumin and blocked with bovine serum albumin. The antibody $\left(18 \mu\right.$ well $^{-1}$ of a 1000 -fold dilution of rabbit anti-domoic acid serum) was added and incubated at room temperature for $1 \mathrm{~h}$. Following washing with high ionic strength solution, $210 \mu$ l of a 1000 -fold dilution of horseradish peroxidase conjugated with goat anti-rabbit immunoglobulin (GIBCO) was added to each well; these were incubated for $1 \mathrm{~h}$, and then washed again. The substrate solution $\left(210 \mu \mathrm{l}\right.$ well $\left.{ }^{-1}\right)$, consisting of $50 \mathrm{mM}$ citrate buffer ( $\mathrm{pH} \mathrm{5.0),} \mathrm{o-phenyl-}$ endiamine- $\mathrm{HCl}$ and $\mathrm{H}_{2} \mathrm{O}_{2}$, then was dispensed to each well the enzyme reaction was terminated by the addition of $50 \mu \mathrm{l}$ of $2.5 \mathrm{~N} \mathrm{H}_{2} \mathrm{SO}_{4}$ after incubation for $10 \mathrm{~min}$; absorbance was recorded then by microplate reader (Thermo Max, Molecular Devices) using $490 \mathrm{~nm}$ sample wavelength and $620 \mathrm{~nm}$ reference wavelength. The standard curve was obtained by dispensing a series of authentic domoic acid concentrations (Diagnostic Chemicals Ltd) in place of samples. Each sample and standard domoic acid concentration was assayed in duplicate or triplicate. Domoic acid production in the whole cultures of Pseudo-nitzschia multiseries was expressed as cellular and/or filtrate domoic acid; domoic acid in picograms per cell (pg cell-1) was calculated by dividing the total domoic acid produced by the number of algal cells per unit assayed.

\section{RESULTS}

The growth of Pseudo-nitzschia multiseries alone or in the presence of varying combinations of proline, glutamic acid, gluconic acid/gluconolactone or bacteria is shown in Fig. 1a and the domoic acid production in Fig. 1b. Evident in the growth curves is the fact that the axenic culture without additives exhibited more rapid and substantially greater growth than did the non-axenic culture (i.e. axenic culture plus additions of Alteromonas and Moraxella sp.l. None of the 3 additives (proline, glutamic acid or gluconic acid/gluconolactone), when added singly at these concentrations, appeared to affect growth greatly. The combination of gluconic acid/gluconolactone with glutamic acid, however, repressed growth markedly. When proline was added to cultures along with gluconic acid/giuconolactone, growth was repressed in the early stages, but not as much in the later stages as it had been by the combination containing glutamic acid.

It can be seen in Fig. $1 \mathrm{~b}$ and Fig. 2 that the largest quantity of domoic acid was produced by the axenic culture supplemented with gluconic acid/gluconolactone; this was close to double the quantity produced by the non-axenic culture and several times greater than that produced by the axenic culture without additives. Apparently the addition of either proline or glutamic acid in combination with gluconic acid/gluconolactone suppressed not only Pseudo-nitzschia multiseries growth, but also the stimulatory effect gluconic acid/gluconolactone had on domoic acid production (Fig. 1). Interestingly the domoic acid in these trials was partitioned between the culture filtrate and the cells (Fig. 2); as the stationary phase of growth was reached the proportion of the domoic acid which appeared in the culture filtrates increased markedly.

As can be seen in Fig. 3a the range of gluconic acid/gluconolactone concentrations had very little effect on the growth of Pseudo-nitzschia multiseries, but had a major impact on the production of domoic 


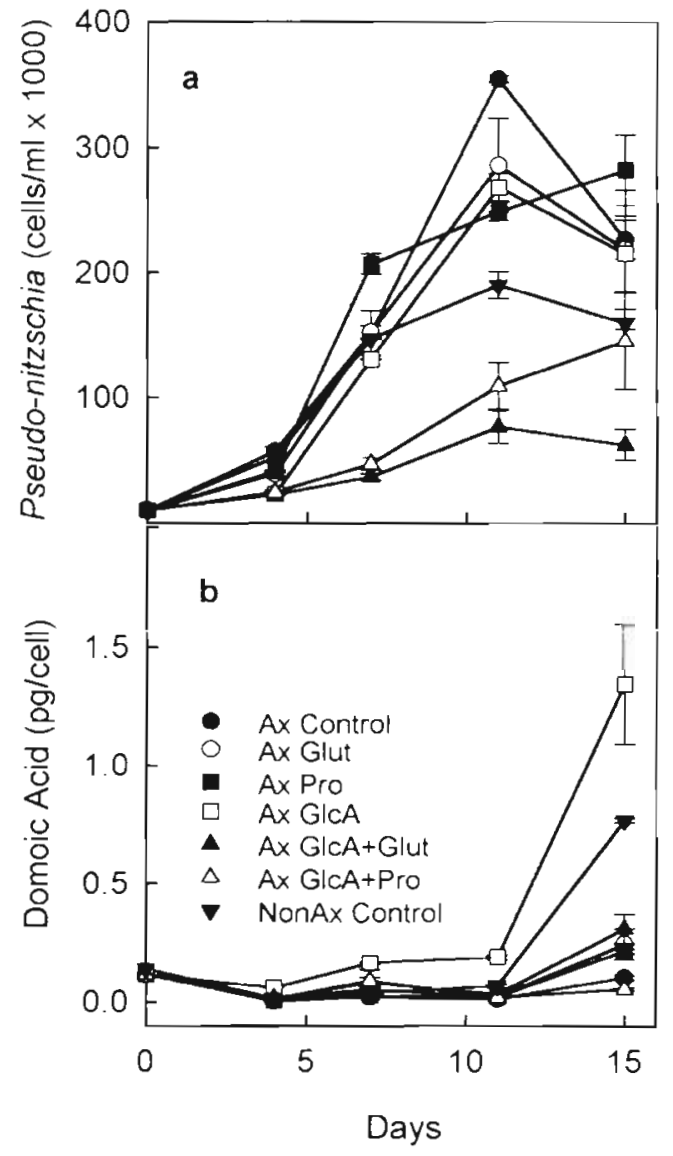

Fig. 1. Pseudo-nitzschia multiseries. Effects on (a) growth and (b) domoic acid production of axenic (Ax) cultures by $5 \mathrm{mM}$ concentrations of glutamic acid (Glut), proline (Pro) and/or gluconic acid/gluconolactone (GlcA). The non-axenic (NonAx) culture control consisted of $P$. multiseries plus Alteromonas and Moraxella sp. Error bars are $\pm \mathrm{SE}(n=2)$

acid (Fig. 3b, c). Total domoic acid production increased with increasing concentrations of gluconic acid/gluconolactone up to about $0.5 \mathrm{mM}$; once more the domoic acid released to the culture filtrates was greater at the higher concentrations of gluconic acid/gluconolactone than at the lower; again the addition of proline suppressed the stimulatory effect of the gluconic acid/gluconolactone. As shown in Fig. 3c even a brief increase in the incubation period $(4 \mathrm{~d})$ in the stationary phase increased considerably the amount of domoic acid produced.

A subsequent experiment using non-axenic cultures (i.e. the axenic culture plus Alteromonas and Moraxella sp:; Fig. 4) illustrated that although neither gluconic acid/gluconolactone nor proline added singly had an appreciable effect upon pseudo-nitzschia multiseries growth in the presence of these 2 bacterial strains (Fig. 4a), the proline had a marked stimulatory impact on the growth of the bacteria in the culture

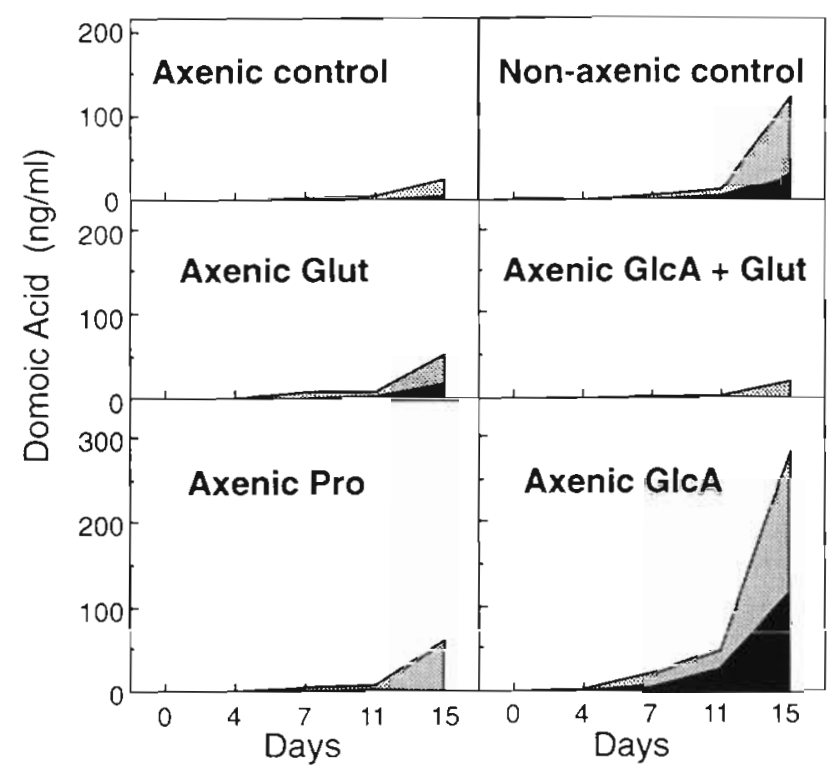

Fig. 2. Pseudo-nitzschia multiseries. Release of domoic acid to the culture filtrate. The total domoic acid produced by the cultures illustrated in Fig. 1 (except for the axenic GicA plus proline) is shown divided between the filtrate domoic acid (shaded areas), and cellular domoic acid (black areas). Abbreviations as in Fig. 1

(Fig. 4b). Once more the production of domoic acid was shown to be enhanced by the presence of gluconic acid/gluconolactone (Fig. 4c); it was 2.5 times greater than that produced in the culture without the additive. Proline again suppressed domoic acid production.

\section{DISCUSSION}

Douglas \& Bates (1992) stated 'microbial involvement is not essential for growth or for DA (domoic acid) production by $N$. pungens f. multiseries'. Our results confirm their conclusions and show in Fig. 1 that this diatom, Pseudo-nitzschia multiseries, in this instance actually grew much better in the axenic control culture (no additives) than it did in the non-axenic control culture (also grown without additives). It should be noted however (Fig 1), that the non-axenic control culture, although not growing as well, produced 5 times more domoic acid than was produced in the axenic control culture. As cited by Douglas \& Bates (1992) a number of authors have noted that domoic acid production is quite variable depending upon the circumstances of growth and the stages of the growth cycle. In our study, as in those by Douglas \& Bates (1992) and Bates et al. (1995), it was usual to find significantly higher levels of domoic acid produced when bacteria were present in the culture than when they were absent. The amounts of growth and domoic acid produced 


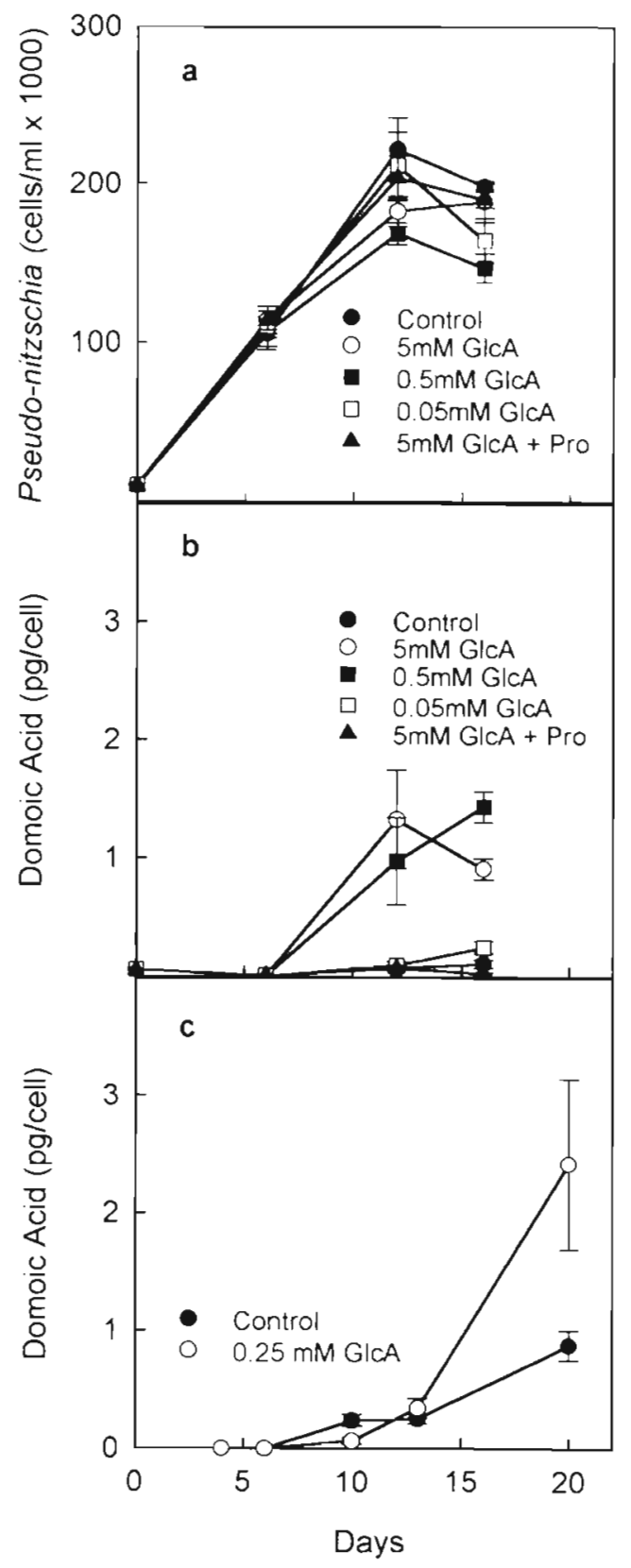

Fig. 3. Pseudo-nitzschia multiseries. Effects of various gluconic acid/gluconolactone concentrations on growth and domoic acid production in axenic cultures. Error bars are \pm SE $(\mathrm{n}=3)$. Abbreviations as in Fig. 1

here by axenic cultures of $P$. multiseries in the presence of gluconic acid/gluconolactone are almost identical to the concentrations of domoic acid reported by Bates et al. (1995) for the same incubation periods for axenic cultures to which specific bacterial isolates were reintroduced. Interestingly, these authors showed that the domoic acid production varied depending upon the particular bacterium reintroduced; the pro-

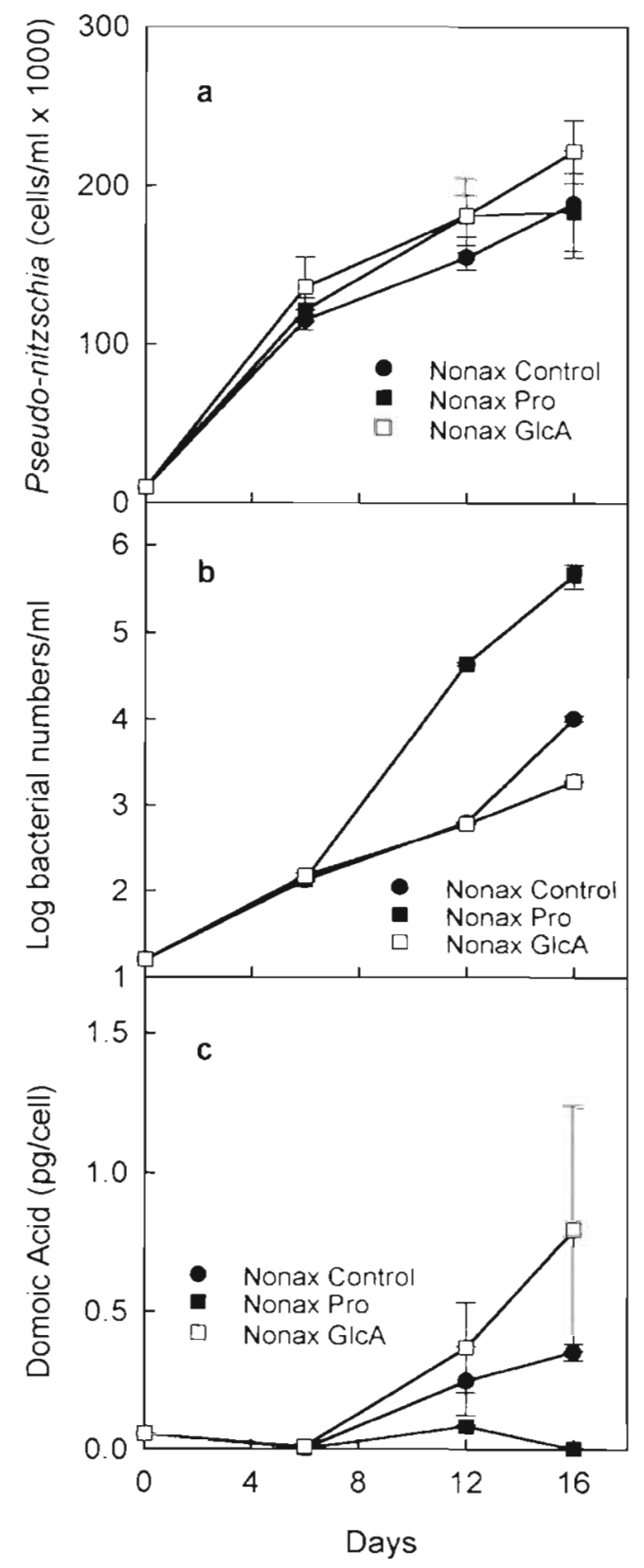

Fig. 4. Pseudo-nitzschia multiseries. Growth and domoic acid production of non-axenic cultures (i.e. includes Alteromonas and Moraxella sp.), and growth of Alteromonas plus Moraxella $\mathrm{sp}$. in the presence of $5 \mathrm{mM}$ gluconic acid/gluconolactone or $5 \mathrm{mM}$ proline added on Day 6 of the growth period. Error bars are $\pm \mathrm{SE}(\mathrm{n}=3)$. Abbreviations as in Fig. 1

duction of domoic acid by those cultures with the native microflora exceeded by a considerable margin those with a single species of reintroduced bacteria. Presumably the bacterial influence is related to a factor(s) produced in the association with the diatom. One such bacterially produced factor influential in domoic acid production is gluconic acid/gluconolactone. 
Of considerable interest and probable importance is the fact that, as growth proceeded, increasing amounts of domoic acid were released by the diatom to the surrounding medium. This is in accord with the findings of Subba Rao et al. (1990), Bates et al. (1991) and Pan et al. (1996a, b, c). In fact, Bates et al. (1991) and Pan et al. (1996a) showed that in the very late stages of prolonged stationary growth the proportion of domoic acid in the culture filtrates rose to between 75 and $85 \%$ of the total produced. Pan et al. (1996a) suggested that the increased release of domoic acid might be a product of defective cell membranes resulting from nutritional deficiencies, in their example, phosphate. Clearly, in the studies cited above, nutritional deficiencies resulted in reduced growth and an earlier onset of the stationary phasc which was accompanicd by an earlier and greater total production of domoic acid. The partitioning of the domoic acid between the cells and the surrounding fluid, however, does not appear to be a simple function of nutritional deficiencies. The data in Fig. 2 illustrate that release of domoic acid occurred even in the very early growth stages in the complete medium as well as when the medium was altered with varying combinations of simple additives such as amino acids, gluconic acid/gluconolactone or bacteria. Thus maintenance of domoic acid levels in the surrounding medium appears to be the norm; its concentration increases with growth and presumably nutrient exhaustion as the diatom enters the stationary growth phase.

Although the effect of gluconic acid/gluconolactone on domoic acid production is concentration dependent (Fig. 3) it does not have a marked effect on growth of either Pseudo-nitzschia multiseries or bacteria in the non-axenic culture (Fig. 4b). It was also shown in a preliminary experiment that domoic acid production was enhanced in cultures containing glucose and Alteromonas sp. (a gluconic acid/gluconolactone producing bacterium), but not in those cultures containing glucose and Moraxella sp. (a nonproducer of gluconic acid/gluconolactone) (authors' unpubl. results).

One question that remains unanswered is the reason for the sparing action of proline or glutamic acid on the induction of domoic acid by gluconic acid/gluconolactone (Figs. 1 to 4 ). Combinations of gluconic acid/gluconolactone with either proline or glutamic acid gave identical results and were just as effective in axenic as in non-axenic cultures. In addition, these combinations repressed Pseudo-nitzschia multiseries growth in the axenic cultures. This suggests that the effect was primarily upon the diatom and not upon the bacteria. The fact that proline and glutamic acid had approximately the same effects is not surprising as metabolically the two are readily interconvertible; Laycock et al. (1989) showed that glutamic acid was present in substantially higher concentrations than proline in domoic acid producing Nitzschia pungens (presumably a strain of $P$. multiseries) cells grown in non-axenic cultures. Thus, it is probable that the final effect resulting from the addition of either amino acid could be attributable more to glutamic acid than to proline.

The collaborative studies with McLachlan and Lawrence had suggested a bacterial source for gluconolactone. Further work by Stewart et al. (1997) showed that the bacteria closely associated with Pseudonitzschia multiseries always included at least 1 species capable of producing gluconic acid/gluconolactone from glucose and that $P$. multiseries contained free glucose and sorbitol. Thus all the necessary ingredients would be avalable for the production of gluconic acid/gluconolactone under the circumstances wherein McLachlan et al. (1993) detected gluconolactone in the domoic acid-laced mussels, i.e. a source of glucose from the diatom and a bacterial agent capable of converting the glucose to gluconic acid/gluconolactone.

At this stage we do not have a proven explanation for the induction of domoic acid production in Pseudonitzschia multiseries by gluconic acid/gluconolactone. Enough information is available, however, to permit limited speculation. Various studies have shown that although different strains of $P$. multiseries yield varying amounts of toxin, all have 1 element in common, they tend to produce domoic acid mainly after growth has entered the stationary phase. This phase occurs after the nutrients sustaining exponential growth are depleted or culture conditions have deteriorated, i.e. when the culture has entered a period of physiological stress. When $P$. multiseries was grown in media in which the concentrations of phosphorus or silica were below the required optimum, domoic acid production was enhanced; this enhancement of domoic acid was eliminated proportionately by adding to the growth medium graded amounts of phosphorus or silica, thereby overcoming nutrient stress (Pan et al. 1996b, c). Another influence is the ammonium concentration; Bates et al. (1993) showed that very high concentrations of this ion tended to inhibit growth of $P$. multiseries compared to growth with the same nitrogen levels in the form of nitrate, thereby initiating the stationary growth phase earlier and at a lower total number of cells. The smaller number of cells that did grow, however, produced higher concentrations of domoic acid than did those growing in the presence of nitrate alone. Thus domoic acid production and its release from the diatom to the surrounding medium are enhanced directly by nutrient reduction brought about by the exhaustion of the nutrient supply through growth, limited initial supply or excessive concentrations of otherwise suitable nutrients (e.g. ammonium ion). 
Gluconic acid is a powerful sequestering agent and for that reason is produced commercially for inclusion in cleaning compounds; domoic acid, as well, has the structure of a powerful chelating agent. We suggest, on the basis of the evidence cited above, that the true function of algally produced domoic acid could be to act on behalf of the diatom as an external chemical scavenger for nutrients and that any agent or condition which limits growth or metabolism stimulates greater production of domoic acid by the diatom. Under particular circumstances gluconic acid could act as such a stimulant in relation to growth and metabolism of the diatom through sequestering and thus limiting nutrients required by the algae. Studies are under way to resolve these points and have provided preliminary evidence that tends to reinforce this hypothesis.

Acknowledgements. We thank Drs W. G. Harrison, W. K. W. Li and D. J. Scarratt for thelr constructive criticism of the manuscript. M.O. thanks the Japanese Ministry of Education, Science and Culture for financially supporting him overseas as a research scientist and wishes to express his gratitude to the Bedford Institute of Oceanography, Department of Fisheries and Oceans, Canada, for accepting him as a Visiting Scientist.

\section{LITERATURE CITED}

Bates SS, and 16 others (1989) Pennate diatom Nitzschia pungens as the primary source of domoic acid, a toxin in shellfish from eastern Prince Edward Island, Canada. Can J Fish Aquat Sci 46:1203-1215

Bates SS, de Freitas ASW, Milley JE, Pocklington R, Quilliam MA, Smith JC, Worms J (1991) Controls on domoic acid production by the diatom Nitzschia pungens f. multiseries in culture: nutrients and irradiance. Can J Fish Aquat Sci 48:1136-1144

Bates SS, Douglas DJ, Doucette GJ, Leger C (1995) Enhancement of domoic acld production by reintroducing bacteria to axenic cultures of the diatom Pseudo-nitzschia multiseries. Natural Toxins 3:428-435

Bates SS, Worms J, Smith JC (1993) Effects of ammonium and nitrate on growth and domoic acid production by Nitzschia pungens in batch culture. Can J Fish Aquat Sci 50:1248-1254

Bird CJ, and 37 others (1988) Identification of domoic acid as the toxin agent responsible for the P. E. I. contaminated mussel incident. Atlantic Res Lab Tech Rep 56:1-86

Douglas DJ, Bates SS (1992) Production of domoic acid, a neurotoxic amino acid, by an axenic culture of the marine diatom Nitzschia pungens f. multiseries Hasle. Can J Fish Aquat Sci 49:85-90

Harrison PJ, Waters RE, Taylor FJR (1980) A broad spectrum artificial seawater medium for coastal and ocean phytoplankton. J Phycol 16:28-35

Hasle GR (1995) Pseudo-nitzschia pungens and P. multiseries (Bacillariophyceae): nomenclatural history, morphology, and distribution. J Phycol 31:428-435

Responsible Subject Editor: J. T. Hollibaugh, Tiburon, California, USA
Laycock MV, de Freitas ASW, Wright JLC (1989) Glutamate agonists from marine algae. J Appl Phycol 1:113-122

McLachlan DG, Lawrence AH, Elias L (1993) Rapid IMS analysis for the shellfish biotoxin, domoic acid. Abstract. 39 th Canadian Spectroscopy Conference. Spectroscopy Society of Canada, Ottawa

Osada M. Marks LJ, Stewart JE (1995) Determination of domolc acid by two different versions of a competitive enzyme-linked immunosorbent assay (ELISA). Bull Environ Contam Toxicol 54:797-804

Pan Y, Subba Rao DV, Mann KH (1996a) Changes in domolc acid production and cellular chemical composition of the toxigenic diatom Pseudo-nitzschia multiseries under phosphate limitation. J Phycol 32:371-381

Pan Y, Subba Rao DV, Mann KH, Brown RG, Pocklington R (1996b) Effects of silicate limitation on production of domoic acid, a neurotoxin, by the diatom Pseudo-nitzschia multiseries. 1. Batch culture studies. Mar Ecol Prog Ser 131:225-233

Pan Y, Subba Rao DV, Mann KH, Li WKW, Harrison WG (1996c) Effects of silicate limitation on production of domoic acid, a neurotoxin, by the diatom Pseudo-nitzschia multiseries. II Continuous culture studies. Mar Ecol Prog Ser 131:235-243

Perl TM, Bedard L, Kosatsky $T$, Hockin JC, Todd ECD, McNutt LA, Remis RS (1990) An outbreak of toxic encephalopathy caused by eating mussels contaminated with domoic acid. N Eng J Med 322:1775-1780

Quilliam MA, Sim PG, McCulloch AW, Mclnnes AG (1989) High performance liquid chromatography of domoic acid, a marine neurotoxin, with application to shellfish and plankton. Int J Environ Anal Chem 36:139-154

Stewart JE, Marks LJ, Wood CR, Risser SM, Gray S (1997) Symbiotic relations between bacteria and the domoic acid producing diatom Pseudo-nitzschia multiseries and the capacity of these bacteria for gluconic acid/gluconolactone formation. Aquat Microb Ecol 12:211-221

Subba Rao DV, Quilliam MA, Pocklington R (1988) Domoic acid - a neurotoxic amino acid produced by the marine diatom Nitzschia pungens in culture. Can J Fish Aquat Sci 45:2076-2079

Subba Rao DV, de Freitas ASW, Quilliam MA, Pocklington R, Bates SS (1990) Rates of production of domolc acid, a neurotoxic amino acid in the pennate marine diatom Nitzschsa pungens. In: Granéli E, Sundström B. Edler L, Anderson DM (eds) Toxic marine phytoplankton. Elsevier, New York, p 413-417

Todd ECD (1990) Amnesic shellfish poisoning - a new seafood toxin syndrome. In: Granéli E, Sundström B, Edler L, Anderson DM (eds) Toxic marine phytoplankton. Elsevier, New York, p 504-508

Todd ECD (1993) Domoic acid and amnesic shellfish poisoning - a review. J Food Prot 56:69-83

Villac MC, Roelke DL, Villareal TA, Fryxell GA (1993) Comparison of two domoic acid-producing diatoms: a review. In: van Dam H (ed) 12th International Diatom Symposium. Hydrobiologia 269/270:213-224

Windholz M (ed) (1983) The Merck Index, 10th edn. Merck \& Co, Inc, Rahway, NJ

Wright JLC, and 18 others (1989) Identification of domoic acid, a neuroexcitatory amino acid, in toxic mussels from eastern Prince Edward Island. Can J Chem 67:481-490

Manuscript first received: March 11, 1996

Revised version accepted: March 21, 1997 